
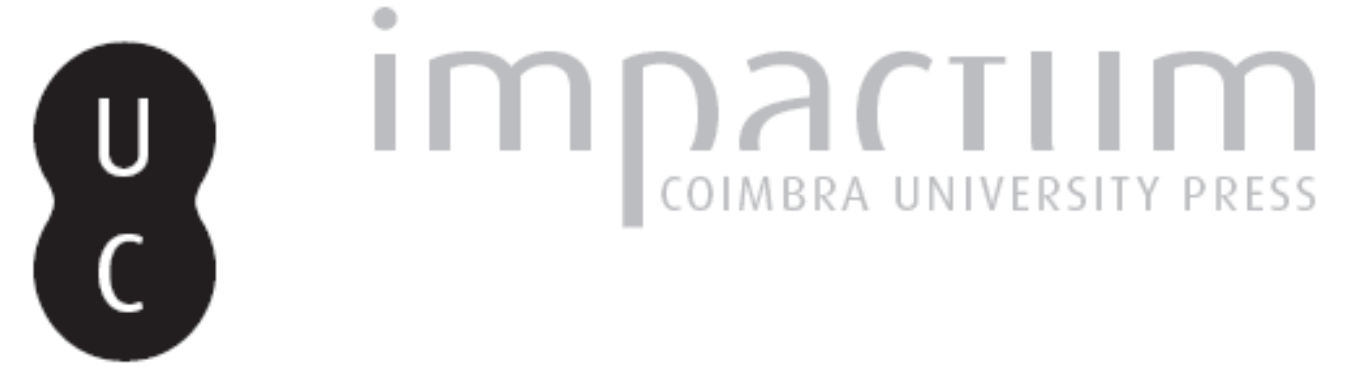

\title{
Quem existe e como existe no jornalismo: análise dos discursos sobre transexualidade e travestilidade em dois jornais de Recife/Brasil
}

Autor(es): $\quad$ Caeiro, Rui; Rocha, Heitor

Publicado por: Imprensa da Universidade de Coimbra

URL persistente:

URI:http://hdl.handle.net/10316.2/39639

DOI:

DOI:http://dx.doi.org/10.14195/2183-5462_29_13

Accessed : $\quad$ 26-Apr-2023 11:05:03

A navegação consulta e descarregamento dos títulos inseridos nas Bibliotecas Digitais UC Digitalis, UC Pombalina e UC Impactum, pressupõem a aceitação plena e sem reservas dos Termos e Condições de Uso destas Bibliotecas Digitais, disponíveis em https://digitalis.uc.pt/pt-pt/termos.

Conforme exposto nos referidos Termos e Condições de Uso, o descarregamento de títulos de acesso restrito requer uma licença válida de autorização devendo o utilizador aceder ao(s) documento(s) a partir de um endereço de IP da instituição detentora da supramencionada licença.

Ao utilizador é apenas permitido o descarregamento para uso pessoal, pelo que o emprego do(s) título(s) descarregado(s) para outro fim, designadamente comercial, carece de autorização do respetivo autor ou editor da obra.

Na medida em que todas as obras da UC Digitalis se encontram protegidas pelo Código do Direito de Autor e Direitos Conexos e demais legislação aplicável, toda a cópia, parcial ou total, deste documento, nos casos em que é legalmente admitida, deverá conter ou fazer-se acompanhar por este aviso.

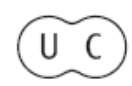




\section{Media Jornalismo}

\section{MÉDIA E COLONIALISMO(S)}




\author{
QUEM EXISTE E COMO EXISTE NO JORNALISMO: \\ ANÁLISE DOS DISCURSOS SOBRE TRANSEXUALIDADE E \\ TRAVESTILIDADE EM DOIS JORNAIS DE RECIFE/BRASIL
}

\author{
WHO THEY ARE AND HOW THERE IN JOURNALISM: \\ ANALYSIS OF THE DISCOURSE ON TRANSSEXUALITY AND \\ TRAVESTISM IN TWO NEWSPAPERS OF RECIFE / BRAZIL
}

\title{
RUI CAEIRO
}

UNIVERSIDADE FEDERAL DE PERNAMBUCO

RECIFE, PERNAMBUCO

CEP52020-212 BRASIL

RUI.CAEIR021@HOTMAIL.COM

\section{HEITOR ROCHA}

UNIVERSIDADE FEDERAL DE PERNAMBUCO/DEPARTAMENTO DE COMUNICAÇÃO SOCIAL RECIFE, PERNAMBUCO

CEP52020-212 BRASIL

HCLROCHA@GMAIL.COM

\section{Resumo}

Compreendendo o jornalismo (nas sociedades ocidentais) como uma instituição que, na sua forma atual, é resultado tanto dos progressos políticos que possibilitaram a afirmação das democracias como sistemas hegemônicos, quanto dos avanços do capitalismo e colonialismo, propomos algumas reflexões para pensar esse paradoxo fundamental, que condiciona as leituras e realizações do jornalismo contemporâneo. Para tal, tomamos como objeto de análise os discursos que Jornal do Commercio e Aqui PE - dois jornais pernambucanos - veiculam sobre transexualidade e travestilidade. Olhando esses fenômenos como legitimadores de violências e marginalização social (tal como são historicamente construídos no ocidente e hegemonicamente reproduzidos), e apontando o jornalismo como espaço privilegiado de lutas pela visibilização e significação da realidade social, questionamos: onde, e de acordo com que racionalidade, sujeitos de gênero não-conforme existem por/ para essa instituição? 0 trabalho é fundamentado nas Teorias Construtivistas do Jornalismo, bem como nas Teorias Subalternas (principalmente Estudos Queer, mas também Estudos Pós-Coloniais).

\section{PaLAVRas-chaVe}

Jornalismo; Transexualidade; Travestilidade; Construtivismo; Colonialismo; Subalternidade. 


\section{Abstract}

Considering journalism (in Western societies) as an institution that, in its present form, results from both the political progress that made possible the affirmation of democracy as a hegemonic system, as the advances of capitalism and colonialism, we propose some reflections about this fundamental paradox which conditions the readings and achievements of contemporary journalism. To this end, as object of analysis we consider the discourses that Jornal do Commercio and Aqui PE - two Pernambucan newspapers - publish about transgender people. Looking at those phenomena as legitimizing violence and social marginalization (as they are historically constructed in the West and hegemonically reproduced), and pointing journalism as privileged space for struggles of visibility and significance of social reality, we ask: where, and according to which rationality, does nonconforming gender people exist for/to that institution? The work is based on the Constructivist Theories of Journalism and the Subaltern Theories (Queer Studies and Postcolonial Studies).

\section{KEYWORDS \\ Journalism; Transgender; Constructivism; Colonialism; Subalternity.}

\section{INTRODUÇÃo.}

Produzir notícias. Essa é, normalmente, a primeira tarefa que candidatas/os a jornalista incorporam como obrigação. É também a expectativa que a audiência cultiva em relação ao jornalismo: ser informada sobre os acontecimentos que, de alguma forma, importam para seu mundo e, principalmente quando os fenômenos reportados rompem com os sentidos já-estabelecidos, ser auxiliada na interpretação e acomodação de tais alterações à(s) sua(s) realidade(s), (re)orientando a compreensão e (inter)ação social.

Afirmamos, assim, que a profissão é sedimentada em cima de três funções centrais, desempenhadas simultaneamente: mediação (entre os sujeitos dispersos no tecido social, os quais, mediante as distintas posições que ocupam na sociedade, no jornalismo encontram - encontram? - um meio de conexão entre realidades e demandas que de outra forma seria mais difícil de realizar); socialização (por meio das estórias tornadas públicas, a vida pode ser discutida, os sujeitos escapam ao isolamento social, constroem laços, identificações e distanciamentos); e interpretação (as notícias não espelham os acontecimentos - todo o processo, desde a percepção até à divulgação, é permeado por seleções e interpretações que formatam a mensagem e seus significados possíveis). Ainda antes de, por influência das Teorias Subalternas, analisar estas considerações - faremo-lo na terceira parte deste artigo, onde nos debruçamos sobre as construções discursivas que dois jornais pernambucanos elaboram sobre mulheres e homens transexuais e travestis -, julgamos pertinente uma breve contextualização histórica da instituição a que nos referimos.

0 jornalismo contemporâneo, considera Correia (1998), tem início no século XVI e irá atravessar diferentes estádios até chegar aos nossos dias. 0 jornalismo partidário (originalmente nomeado de party press), como seu nome indica, estava explicitamente vinculado a projetos políticos e/ou econômicos, sendo assim normalmente associado a um papel de simples reprodução de mensagens afetas a essas esferas. Apesar dos debates serem limitados a assuntos e interesses concretos, 
reproduzindo a exclusão de largas parcelas populacionais da discussão (e existência) pública, reconhecemos o papel que desempenhou na promoção de uma sociedade menos centralizada em preceitos religiosos. Impulsionado pelo lluminismo, 0 jornalismo instituiu-se como espaço privilegiado para a "discussão racional, para 0 questionamento permanente, para a vontade de saber mais" (Coelho, 2015: 22).

Não será, portanto, surpreendente notar que, desde a sua gênese, o habitat preferencial do jornalismo é a urbe, os lugares centrais (Tuchman, 1983), onde, para além de maior densidade populacional, se firmam as instituições que mais diretamente intervêm (política, econômica e culturalmente) na sociedade. Atrelada à centralidade geográfica está a centralidade do poder e a visibilidade pública. Essa dicotomia (centro/periferia, sujeitos que falam/ sujeitos que são falados), alavancada pela industrialização e reforçada no capitalismo, irá condicionar - se não justificar - a instituição de valores, normas e métodos hegemônicos da (então não assim considerada) profissão. 0 jornalismo surge assim como instituição integrante de um sistema colonialista que, desde 0 início, foca atenção nos assuntos, enquadramentos e sujeitos considerados legítimos, pelas posições que ocupam dentro dessa ordem social, para discutir os mundos por um viés ocidental, em que as vozes tornadas públicas são justificadas com base numa objetividade 'pura', que dá a conhecer o mundo 'tal como ele é' (o debate em torno dos silêncios dá-se, portanto, via da regra, em torno daqueles a que é reconhecida existência pública, e que por isso é percebida sua ausência, e não daqueles em relação aos quais as racionalidades normativas se constituem, pois a naturalização dos mundos, não estranha à constituição de subalternidades, é operada enquanto espaço em relação ao qual se estabelece, em maior ou menor grau, o consenso da rejeição de escuta).

Vários são os fatores que contribuem para a passagem do jornalismo considerado predominantemente opinativo (identificável com o jornalismo partidário) para o jornalismo considerado predominantemente noticioso (identificável com a penny press, ou jornalismo mercantil, como preferimos nomear). Aqui destacamos

os económicos (como, por exemplo, desenvolvimento da economia de mercado, novas formas de financiamento, desenvolvimento da publicidade enquanto fonte de receitas), sociais (como, por exemplo, crescimento da população urbana, escolarização em massa, alfabetização das camadas populares, instituição de escolas públicas, urbanização, desenvolvimento de vias de comunicação terrestres e marítimas), políticos (como, por exemplo, desenvolvimento de governos democráticos - para Nelson Traquina, a relação entre jornalismo e democracia é simbiótica, a liberdade aparece como valor central -, conquista de direitos fundamentais, reconhecimento da liberdade e da democracia como conceitos basilares, reconhecimento da liberdade de imprensa) e industriais/tecnológicos (como, por exemplo, desenvolvimento dos correios e telecomunicações, domínio da técnica tipográfica e aperfeiçoamento das rotativas, rapidez de transmissão da informação ligada ao telégrafo, melhoria na reprodução de imagens - aperfeiçoamento da fotografia) (Lopes, 2010: 2).

0 nome pelo qual ficou conhecido - 'imprensa do tostão' (penny press), se literalmente traduzido - dá-nos subsídios para compreender a expansão do seu raio de ação. Acessível a um público mais alargado (portanto mais heterogêneo e disper- 
so), em que sujeitos com menores níveis de escolaridade, menor poder aquisitivo e jornadas de trabalho mais longas (normalmente, também mais exigentes fisicamente) se tornam em possíveis (e desejáveis) consumidores, o jornalismo torna-se mais leve (porque assim são percebidas - definidas? - as necessidades do novo público). A leitura/definição de classe social torna-se fulcral para a percepção e constituição do público, ficando outros marcadores, como gênero, relegados para mais tarde. Neste processo, o jornalismo não se limita a adequar-se aos (supostos) interesses e identidade do(s) novo(s) público(s) - isto significaria a demissão de reconhecer as funções que nele, inicialmente, identificámos -, antes tem papel ativo na definição dos mesmos.

Compreendido como um complexo processo histórico, que obviamente não termina no presente, o jornalismo contemporâneo é marcado por contradições decorrentes das condições em que é exercido. Rocha (2008: 41) aponta seu caráter ambíguo fundamental: legitimado pelo interesse público e impulsionado pelo capital (o elo é a audiência em número cada vez maior), o jornalismo ocupa posição central nas discussões sobre abusos de poder e estratégias de resistência, ora percebido como instrumento de um, ora defendido como instrumento de outro. Nesse debate, o desafio é, sem incorrer em desresponsabilizações (portanto, assujeitamentos totalitários), compreender a mídia como um dos locais em que, e por que, estruturas de poder se materializam, mas não onde, de forma isolada, têm origem ou fim.

Os produtos midiáticos, em que estão contemplados os diversos gêneros jornalísticos, funcionam como janelas para o mundo. Como tal, a percepção deste depende

de se a janela é grande ou pequena, se tem muitos ou poucos cristais, se 0 vidro é opaco ou claro, se a janela é voltada para uma rua ou um pátio. A cena depende também da posição do sujeito que observa, se longe ou perto, se movendo o pescoço para diferentes direções ou mantendo-o reto, direcionado para a frente [...] (Tuchmann, 1983: 13, tradução nossa).

A metáfora de Tuchmann dá-nos conta da recusa em perceber o jornalismo como instituição neutra, mera descritora de uma realidade universal, objetiva e imparcial, que opera sem interferências culturais e ideológicas. Por outras palavras, as 'janelas', portanto, "a "realidade» e a «informação» são entendidas como construções sociais e não como um conjunto de dados preexistentes" (Correia, 2011: 143). Ainda que esta leitura, construtivista, não encontre tantas resistências como anteriormente, quando o consenso hegemônico estava estabelecido em torno da perspectiva objectivista, as consequências dessa virada epistemológica são menos 'vistosas' do que poderia ser expectável. Para justificar esta consideração, tomamos como exemplo os discursos que Jornal do Commercio (JC) e Aqui PE colocam em circulação a respeito de homens e mulheres transexuais e travestis.

Ainda antes de nos debruçarmos sobre os aspetos metodológicos, frisamos que ao nos referirmos a travestis neste trabalho, estamo-nos a referir a uma identidade/ identificação característica da América Latina (e, aqui, mais concretamente do Brasil), e que portanto tem significado diferente face a outras geografias (como é 0 caso de Portugal). Assim, por travesti compreendemos qualquer pessoa que assim se identifique (por razões variadas, que a cada sujeito dizem respeito), face à 
sua não conformidade com o gênero que, ditado pela genitália identificada, Ihe foi imposto ao nascer. Importa ainda referir que a Associação Nacional de Travestis e Transexuais brasileira (ANTRA) comunica que é no feminino que as travestis se sentem respeitadas, devendo portanto assim serem tratadas. Esta posição, contudo, não significa que todas as travestis querem ser tratadas no feminino. Tal como não é possível afirmar, de forma categórica, que travestis são, exclusivamente, aquelas pessoas que à nascença foram nomeadas como homens. Sempre que uma travesti requisite ser tratada com flexão gramatical masculina, tal deve ser atendido, de contrário, quando tal não é possível saber, é defendido que a postura correta a ser adotada é a já definida (ANTRA, 2013).

\section{Aspetos METODOLÓGICOS}

Os dois jornais foram escolhidos para análise por dois motivos fundamentais: 0 elevado número de exemplares que colocam em circulação (de acordo com a Associação Nacional de Jornais, JC e Aqui PE são, desde 2010, os jornais que registram maior número de exemplares em circulação no Estado de Pernambuco, portanto, que têm um alcance de público (e, assim, influência) potencialmente maior) e a diferença dos respectivos púbicos-alvo/consumidor (o primeiro, de custo mais elevado e com um público definido como sendo das classes média-altas, o segundo de custo mais baixo e direccionado para as classes média-baixas). Este último aspeto está relacionado à própria identidade dos veículos: o primeiro identificável com a noção de 'jornalismo de referência' e o segundo com a de 'jornalismo popular.

0 'jornalismo de referência' é, normalmente, relacionado a uma matriz cultural predominantemente racional-iluminista (Sunkel, 1987), que "aborda conflitos histórico-sociais, privilegia um entendimento histórico-social da realidade e pauta assuntos próximos ao 'mundo oficial', ao interesse público" (Amaral, 2006: 72), enquanto 0 'jornalismo popular', mais identificado com uma matriz simbólico-dramática (Sunkel, 1987), é percebido como abordando, predominantemente, "conflitos interpessoais, privilegia[ndo] um entendimento familiar da realidade e pauta[ndo] assuntos próximos à vida privada e cotidiana" (Amaral, 2006: 72). Alinhavamos aqui estas breves definições com o intuito de, para além de uma contextualização dos materiais a analisar, contribuir para a discussão, que consideramos necessária, sobre as relações que os jornalismos estabelecem com os públicos, as relações que os públicos estabelecem com eles e os distanciamentos e aproximações entre ambos (jornalismos e públicos entre si), muitas vezes descritos como mais distantes do que na verdade estão (a diminuição das supostas diferenças pode ser pensada, por exemplo, tendo em conta as notícias que aqui apontamos, referentes a pessoas trans).

No presente trabalho, ao fazer uso do termo 'pessoas trans' referimo-nos a travestis e a mulheres e homens transexuais. Fazemo-lo por ser esse o foco do nosso trabalho, frisando contudo que outras identidades podem ser compreendidas nesse termo guarda-chuva (por exemplo, intersexuais, agender, genderfluid, etc.), que engloba as pessoas que têm seus corpos/ vidas socialmente deslegitimadas face às normas de sexo/gênero impostas em nossa sociedade).

Debruçamo-nos agora mais concretamente sobre o processo de recolha e seleção, que depois nos direcionou à análise, dos textos noticiosos. Através de uma análise exploratória, procuramos primeiro identificar signos lexicais e/ou semân- 
ticos referentes ao universo temático que nos propomos estudar. Em tal análise excluímos as seções relacionadas a cultura e esporte por considerar que nelas é menos provável encontrar discursos com incidência na construção de representações sociais referentes a transexualidade e travestilidade. Devido ao parco material que era expectável encontrar, e devido a limitações de tempo, decidimos balizar o período de análise entre janeiro de 2014 e janeiro de 2015 (estas datas estão relacionadas ao fato de, desde 2004, 29 de janeiro ser celebrado no Brasil como 0 Dia Nacional da Visibilidade Trans), perfazendo assim o total de um ano e um mês. Também devido a essa possibilidade, de (quantitativamente) encontrarmos pouco material para análise, optamos por não delimitar o material em termos de géneros textuais (entrevista, reportagem e notícia), mesmo reconhecendo que as estratégias argumentativas e características organizacionais variam entre eles. Excluímos contudo os textos considerados opinativos (nessas seções dos jornais localizados), uma vez que o nosso foco é na informação considerada 'noticiosa', 'fatual' (por isso a sintetizamos no termo 'notícia').

Sobre a investigação que propomos, é importante também frisar que pretendemos uma análise que não seja limitada às palavras, mas que procure compreender os significados que são produzidos na seleção, interpretação e construção dos discursos jornalísticos. Tomando como ponto de partida os signos textuais, teremos em consideração os contextos socialmente situados, definidores (mas não irremediavelmente determinantes) dos discursos e de suas interpretações. Ou seja, as noções de transexualidade e travestilidade que hegemonicamente são compartilhadas naquele país (e no mundo ocidental em geral).

Seguimos também a sugestão de Rosalind Gill (2002: 265), quando esta assinala a importância de apresentar os materiais analisados aos leitores/participantes/ sujeitos da pesquisa. Referimo-nos, no caso, ao contato com os sujeitos envolvidos na produção dos materiais analisados, que neste artigo introduzimos consoante a pertinência, mas que, independentemente do maior ou menor número de transcrições, condicionam as considerações que tecemos ao longo do artigo. Os sujeitos entrevistados foram selecionados mediante dois parâmetros: os cadernos onde mais encontrámos notícias - que no JC seria Brasil (9) e Cidades (4), e no Aqui PE, Geral (3), Polícia (3) e Cidades (3) - e o cargo desempenhado - no caso, editores/as, principalmente. A posição hierárquica apresenta-se como importante por dois motivos: 1) a grande maioria dos materiais recolhidos não tinham assinatura do/a jornalista, sendo assim muito difícil mapear os/as produtores/as de cada matéria. Mesmo que tal fosse possível, ainda que entrevistas com tais sujeitos, possivelmente, se revelassem interessantes, é sabido que as redações são constituídas por posições hierarquicamente organizadas. Assim, consideramos que 2) os/as editores/as dos cadernos, pela posição que ocupam, podem oferecer-nos melhores índices para compreender as construções discursivas sobre travestilidade(s) e transexualidade(s).

\section{Fala e EScuta no JoRnalismo.}

Para pensar as funções e atuações do jornalismo atual, começamos por apontar a quantidade de notícias para análise (e aqui limitamo-nos aos discursos em que há nomeação expressa e exclusiva da transexualidade e/ou travestilidade): no JC encontramos cinco notícias referentes a pessoas transexuais, uma sobre travestis 
e outra em que as duas categorias identitárias (transexualidade e travestilidade) são acionadas. As notícias que enquadramos na categoria 'transexualidade' são do dia 24 de Janeiro (título: Delegado de polícia troca de sexo em Goiás), 23 de Março (título: Transexuah - a notícia, curta, aborda o caso de "um estudante transexual [...] [que] não quer ser chamado pelo nome de baptismo, William [...]", 28 de março (título: Lea T posa de índia) - vale aqui um apontamento para referir que a notícia, curta, não é referente à transexualidade enquanto fenômeno social mas ao sujeito, que é uma mulher transexual, sendo o foco na sua posição profissional/ social, mais do que na legitimidade, ou não, enquanto mulher -, 5 de Setembro (título: STF julgará identidade de transexuais) e 15 de Outubro (título: União habilita HC para cirurgia de troca de sexo); na categoria 'travestilidade' apenas a notícia de 17 de Junho (título: Travesti é morto em prédio de Boa Viagem) e na categoria 'transexualidade/travestilidade' a notícia de 22 de Janeiro de 2015 (título: Carnaval 2015: vêm aí o Miss América) - é colocada a pauta a tentativa de realização de um concurso de fantasias para travestis e transexuais, "[...] livre de perseguições homofóbicas" (grifo nosso).

No Aqui PE, identificamos quatro notícias com foco em pessoas transexuais, duas em travestis e duas em ambas as identidades. No total das quinze notícias, a fala de pessoas trans surge em quatro ocasiões. Na categoria 'transexualidade': 24 de Janeiro (título: 0 direito de ser "ela") - 0 acontecimento noticiado é 0 mesmo que surge no mesmo dia nas páginas do JC, ou seja, a cirurgia de redesignação genital da uma delegada de Polícia no Estado de Goiás -, 25 de Janeiro (título: Transexual luta por operação) - esta é a única notícia em que o sujeito-notícia é um homem transexual, 4 de Abril (título: Romário obtém vitória contra transexual) e 16 de Outubro (título: Transexuais) - a notícia aborda a habilitação do Hospital das Clínicas, em Recife, para "oferecer atenção especializada no atendimento a transexuais para mudança de sexo" (grifos nossos); na categoria 'travestilidade': 7 de Fevereiro (título: Travesti morto em motel) e 6 de Novembro (título: travesti detido por assalto), na categoria 'transexualidade/travestilidade': 12 de Fevereiro (título: Travesti assassinado na rua) - apesar do título nomear a pessoa como travesti, no corpo da notícia essa classificação é intercalada com a de 'transexual' - e 13 de Maio (título: Travestis poderão usar nome social) ainda que no título apenas surja 'travesti', na notícia é referido que a medida é também destinada a transexuais.

Mais do que frisar a escassez de notícias, que desde logo é um indicador interessante para começar a pensar quais os critérios de noticiabilidade no jornalismo, gostaríamos de pensar os sentidos construídos (por presença e ausência), bem como estes se chegam a constituir. Fazemo-lo através do mapeamento de formações discursivas, estas compreendidas como "uma espécie de região de sentidos, circunscrita por um limite interpretativo que exclui o que invalidaria aquele sentido" (Benetti, 2010: 112, grifos da autora).

Observando os títulos das notícias, podemos perceber que homens e mulheres transexuais - talvez fosse mais correto considerar apenas as mulheres, já que 0 relato referente, especificamente, à transmasculinidade surge uma única vez em todo o período analisado - estão, quase exclusivamente, limitadas a questões referentes à (i)legitimidade de suas identidades. Exemplificamos: 
Sequência Discursiva (SD) 1: Delegado faz mudança de sexo em Goiás.

Cirurgia. Laura assumirá cargo na Delegacia da Mulher. (JC, 24 jan. 2014).

SD2: 0 direito de ser "ela".

Thiago realizou cirurgia de mudança de sexo e deve assumir plantão de Goiânia como Laura (Aqui PE, 24 jan. 2014).

Em ambas as sequências, é o procedimento cirúrgico, não a autodeterminação do sujeito, que é colocado em evidência. A posição das palavras, a construção narrativa, não é aleatória - esse aspeto é especialmente notório na SD1: é a palavra 'cirurgia', isolada das restantes frases, que coordena o sentido. Anterior a ela, 0 sujeito é definido como sendo do gênero masculino - só depois é nomeado como Laura, ou seja, do gênero feminino. A SD2 tem uma construção semelhante: 0 gênero do sujeito é, desde o início, colocado como dúbio, em conflito, através da marcação gráfica com aspas. À cirurgia é atribuída a resolução do impasse, formadora legitima de gênero e nome: já não Thiago, mas Laura.

Para além do foco no procedimento cirúrgico, a atividade profissional/ posição social do sujeito opera enquanto valor-notícia na construção da mesma. Esse fator poderá estar relacionado à não-nomeação do sujeito enquanto transexual, contribuindo dessa forma para a sua exotificação (SD3): policial - atividade socialmente identificada como sendo do universo masculino (e dos seus valores, como seja autoridade e força, entre outros) - retira pênis (símbolo de virilidade, do 'ser homem'). É o genital (e seu significado) que está no centro da notícia, definindo a identidade do sujeito.

SD3: A reportagem mostrou a surpresa de alguns ex-colegas de trabalho. "0 delegado era implacável em ações que exigiam demonstrações de 'macheza' e sua conduta era de um homem que exalava testosterona", declarou um escrivão. (JC, 24 jan. 2014).

Travestis, por outro lado, estão presas, também quase exclusivamente, nas matérias policiais. Reorganizamos os dados colectados e reproduzimos os títulos/lead de todas as notícias em que a palavra 'travesti' (isolada de outras, como 'transexual' ou LGBT) está presente:

SD4: Travesti preso em motel. (Aqui PE, 7 fev. 2014).

SD5: Tejipió. Travesti assassinado na rua. (Aqui PE, 12 fev. 2014).

SD6: ENEM. Travestis poderão usar nome social. (Aqui PE, 13 mai. 2014).

SD7: Travesti é morto em prédio de Boa Viagem. (JC, 17 jun. 2014).

SD8:Barro. Travesti detido por assalto. (Aqui PE, 6 nov. 2014).

Para além do desrespeito à identidadede gênero, das cinco notícias, quatro retratam travestis em um ambiente específico: a criminalidade. Se em duas delas 0 sujeito é colocado como ator (SD4, SD8), em outras duas é colocado como vítima (SD5, SD7). Ainda assim, mesmo quando vítima é colocada ênfase sobre a responsabilidade desta no desfecho do acontecimento (SD9, SD10), tanto por meio do destaque sobre os espaços que ocupa (a rua, a prostituição) como por meio dos atos 
realizados (brigas), reforçando a imagem de violência e transgressão vinculada nas restantes notícias (SD4, SD8). A suposta reincidência dos sujeitos na criminalidade é, também, enfatizada (SD11, SD12).

SD9: Os tiros seriam para Walter Gutemberg Ribeiro da Cunha, 19, que teria se envolvido em uma briga com o travesti. (Aqui PE, 12 fev. 2014).

SD10: De acordo com a Polícia Civil, a vítima, que era travesti, tinha acabado de fazer um programa com o acusado quando foi morto. Ulisses Júnior teria dito que estava sem dinheiro e que iria ao banco sacar uma quantia para pagar o serviço. 0 travesti não teria aceitado, iniciando uma briga com o suspeito. (JC, 17 jun. 2014).

SD11: Jailson já tem passagem pela polícia por tráfico. (Aqui PE, 7 fev. 2014).

SD12: Segundo a polícia, Sabrina piu piu, como é conhecida pelos amigos, era acostumada a fazer programas no Barro. (Aqui PE, 6 nov. 2014).

Estas considerações, tanto a respeito da transexualidade como da travestilidade, estão atreladas a um conjunto de crenças - ou, se preferirmos, conhecimentos -, culturalmente construídas, ideologicamente fundamentadas, de que no corpo está inscrita a 'natureza' e, assim, a 'verdade' do sujeito individual e coletivo. Historicamente, essa premissa, que institucionaliza caracteres biológicos como essenciais e justificadores de diferenças, tem servido bem à reprodução de relações de poder abusivas, alimentando teorias, como bem pontua Louro (1997: 45), “construídas e utilizadas para "provar» distinções físicas, psíquicas, comportamentais; para indicar diferentes habilidades sociais, talentos ou aptidões; para justificar os lugares sociais, as possibilidades e os destinos "próprios»" de cada pessoa e/ou grupo.

Neste contexto, mulheres e homens transexuais são definidas como pessoas com 'corpos errados', dependentes de uma cirurgia para ter seu corpo, portanto, suas vidas reconhecidas. Por outras palavras, quando os corpos não cabem dentro das fronteiras do que na tradição eurocêntrica colonialista foi definido como 'ser homem' e 'ser mulher', eles são patologizados, criminalizados, de maneira a manter a ordem 'natural'. As fronteiras podem, ilusória e momentaneamente, ser expandidas para mais facilmente serem reforçadas. As definições nunca cessam de ser binárias (definindo quais as duas únicas possibilidades de existência/reconhecimento social, constituídas por rígidas fronteiras de identificação/desidentificação - para além da identificação com Outros, que são 'iguais a mim', a constituição é feita através do 'Outro que eu não sou', portanto, através da negação/ afirmação do Outro em relação a mim e de mim em relação ao Outro -, em que um dos elementos do binómio é colocado como central, em relação ao qual é definido seu oposto subalterno: homem/mulher, branco/negro, etc.), biológicas (portanto, pré-discursivas), naturalizadas. Esse poder disciplinar (na esteira de Foucault), mais do que moral, é instrumental, profícuo no controle social, baseado em normas que qualificam e corrigem ao mesmo tempo. Como coloca Miskolci (2005: 13), ela "não visa excluir, antes é a pedra de toque de uma técnica positiva de intervenção e transformação social. Os dissidentes passam a ser classificados e corrigidos". 
0 'direito de ser ela', no caso, de ser mulher - transexual - (em uma alusão à notícia de 24 de Janeiro do Aqui PE), apenas pode começar a ser conjecturado a partir do momento em que o próprio sujeito desiste (ao menos aparentemente) de afirmar o direito sobre seu próprio corpo e reconhece que dele está refém, que seu gênero, que sua identidade, necessita ser construído cirurgicamente.

Com estas considerações não pretendemos, obviamente, deslegitimar o desejo, e direito, de pessoas trans acederem a cuidados de saúde - em que estão enquadradas tecnologias de modelagem dos corpos, dentre elas a cirurgia de redesignação genital (CRG) -, pelo contrário: o que denunciamos é precisamente a retirada dessa autonomia, através do insistente cultivo de um 'regime de verdades', tornado natural, que define quem tem autoridade para falar e dentro de que perspectivas de existência. Tais regimes, definidores de hierarquias e exclusões, exilam os sujeitos que a elas não se adequam, condenando a uma morte em vida (Bento, 2006: 94).

Este fenômeno é também sustentado por uma cultura cientificista, que defende a ciência (como percebida/produzida no ocidente) como autoridade cognitiva exclusiva legitimadora de conhecimento, resultante do

gradativo processo de especialização e representação cientificista de tópicos morais e políticos, [...] [resultando no] estreitamento da esfera pública e na redução da participação democrática. Esta nova ideologia, que transforma a ciência em fetiche, [... ] obscurece as questões práticas, justifica o interesse de dominação parcial de uma classe determinada, oprime aquelas de posição subalterna e compromete o próprio interesse emancipatório da espécie humana (Rocha, 2009: 1-2).

Não pretendemos, naturalmente, rejeitar (todos) os métodos e resultados científicos, mas criticar a "pretensão positivista de tentar erigir o absolutismo da metodologia sob uma rotina fática, [...] que não pressupõe o sujeito que conhece" (Rocha, 2009: 2); simultaneamente, salientamos que a produção de conhecimento pode dar-se em múltiplos espaços, em moldes diversos, com propósitos variados, e que as suas pretensões de validade devem ter em conta não só os argumentos e métodos, como também os contextos e lugares de fala.

Ao mencionarmos 'lugares de fala', pretendemos dar destaque à compreensão de que somos atravessados/as por um vasto leque de experiências e marcadores sociais que condicionam a nossa compreensão e expressão do/no mundo. A interpretação e vivência de tais marcadores (ser mulher e ser negra, por exemplo) é (inter)subjetiva e não- homogênea entre aqueles sujeitos que assim se identificam, contudo a leitura social que deles é feita irá determinar, de forma mais ou menos rígida, a posição (política, mas não só) a ser ocupada na sociedade e, consequentemente, a sua legitimidade para produzir conhecimento sobre determinado assunto. Essas posições podem ser transgredidas, mas nem por isso a leitura social de tais marcadores desaparece por completo: acreditamos que, por ora, o debate principal sobre esta matéria, principalmente nos movimentos sociais, gira em torno da ressignificação (simbólica, portanto material) desses marcadores e não a sua supressão.

Defendemos que é importante refletir sobre quem pode (por ter acesso a recursos socialmente valorizados) e tem legitimidade (pelo lugar de fala que ocupa) para falar sobre determinado assunto, por determinado prisma, visto que esse é um 
exercício realizado, e compreendido, a partir de "um lugar específico nas relações de poder e tomad[0] por marcas destas formações. Entender que o diálogo é uma forma de interação de poder, é perceber também que estes lugares ligam-se diretamente ao que é hegemônico e ao que não é hegemônico" (Vieira, 2015). A noção de 'lugar de fala' está então intimamente relacionada à noção foucaultiana de que os corpos (aqui com enfase nos humanos e nos desumanizados) nunca são 'naturais', aprioristicamente vazios de significados, pois desde sempre são atravessados por inscrições históricas. Assim, o corpo "está diretamente mergulhado num campo político; as relações de poder têm alcance imediato sobre ele, elas o investem, 0 marcam, o dirigem [... ] exigem-Ihe signos" (Foucault, 1999: 25).

Acreditamos que ignorar estas questões, demitirmo-nos da auto-reflexão no processo de consumo e produção de conhecimento, significará um maior risco de reproduzir as "estruturas condicionadoras de poder que, acriticamente, mostram-se como naturais, mas não o são, pois, de fato, são o resultado de uma comunicação sistematicamente distorcida e de uma repressão sutilmente legitimada" (Rocha, 2009: 16). Assim, importa frisar que existem conhecimentos em relação aos quais se instauram recusas de aproximação, recusas de os buscar ou reconhecer. Ao invés do conhecimento, a busca é pela permanência na ignorância. Simultaneamente, podemos afirmar que o conhecimento, ao ser construído, define aquilo que permanece não-dito, não-conhecido. Podemos pensar esta afirmação em relação à transexualidade e travestilidade: ao mesmo tempo que um conjunto de saberes específicos é acionado para as definir, para as 'conhecer', uma extensa produção de conhecimentos (construídos por transfeministas e não só) é relegada à invisibilização, deixando assim à margem a possibilidade de a suposta 'normalidade' de homens e mulheres 'de verdade' ser problematizada. Neste quesito, o jornalismo pode e, no nosso entender, deve assumir, finalmente, sem ressalvas, o seu papel, historicamente constituído, de questionar as estruturas de poder dominantes.

As construções da transexualidade e travestilidade - como hegemonicamente são reconhecidas, em função das instituições que tiveram, e têm, poder para 'oficialmente' as definir (os discursos médico-científicos: endocrinologia, sexologia, psiquiatria, psicologia e psicanálise, principalmente) - se diferenciam por meio do significado que representa a transgressão: definidas como doentes, pessoas transexuais - as 'verdadeiras' - são percebidas como vítimas que se devem submeter a terapias médicas para corrigir o 'desvio' de seus corpos. Travestis diferenciar-se-iam pela sua perversidade: não desejando a correção, mas viver na marginalidade, seriam homens que, com o intuito de obter prazer sexual, adotariam estratégias várias para se aproximarem de uma estética e performance consideradas femininas. Assim, a travestilidade fica conotada à perversão sexual, não à identidade de gênero (ou, no discurso hegemômico, transtorno de identidade de gênero).

Estas construções são reproduzidas pelo jornalismo - ao menos nos dois jornais em análise. A impossibilidade de serem reconhecidas outras narrativas, que é flagrante se observarmos os enquadramentos dos acontecimentos, é sublinhada pela fala de André Galvão, editor no JC:

Galvão: [...] a gente tirou muito noticiário policial da cobertura, só damos espaço para os grandes crimes. 
Caeiro: Que era onde antigamente surgiriam mais notícias sobre [travestis]. . .

Galvão: É, surgiria! Seria mais fácil você ver uma matéria dessa a cada dois meses, a cada... sei lá, uma vez por mês. Então assim, hoje em dia se um travesti for assassinado, "ah, você não vai noticiar!"... eu vou noticiar se for um fato que realmente tenha relevância. (A. Galvão, entrevista pessoal, 29 de dezembro, 2015).

Essa fala dá-nos conta da naturalização dos espaços a que os sujeitos 'pertencem' (no caso, travestis como autoras e/ou vítimas de crimes), que sustenta a (ir) relevância dos acontecimentos: no caso, 0 assassinato de uma pessoa, se travesti, não bastaria para ser transformado em notícia.

Alguns dados são importantes para contextualizar esta naturalização: segundo estimativas recentes da ANTRA (Associação Nacional de Travestis e Transexuais), cerca de $90 \%$ da população trans brasileira trabalha na prostituição; estudos levados a cabo pela Transgender Europe ${ }^{1}$ concluem que o Brasil é o país onde se regista a maior taxa de assassinatos de pessoas trans, quatro vezes superior ao segundo colocado (o México) - a esperança média de vida é entre 30 e 35 anos, menos da metade de pessoas não-trans (cerca de 75 anos). Estes dados, contudo, não têm grande visibilidade e, mesmo quando conseguem ultrapassar as barreiras impostas pela indiferença, são operacionalizados, não raras vezes, de maneira a reforçar a lógica do aparelho normativo: o problema é localizado nos sujeitos, nos ambientes que 'decidem' habitar, no corpo deliberadamente criminoso que rejeita a 'normalidade' (cientificamente construída, utilitariamente manejada, moralmente legitimada), rejeitando considerar o problema como estando localizado nas construções sociais que empurram para a marginalidade corpos específicos, alvos de um genocídio (Jesus, 2014) silenciado, tornado irrelevante. 0 que dizemos é sustentado pelos discursos dos jornais em análise, em que a transexualidade e travestilidade, através da despolitização dos acontecimentos e personalização das demandas (normalmente limitadas à (RG), são produzidas enquanto fenômeno individual.

As vozes que são manejadas na construção dos discursos também constituem um importante caminho a perseguir se pretendemos colocar em destaque os sentidos produzidos. Nesse sentido, ao estudar o significado de 'objetividade' para jornalistas brasileiras/os, Sponholz (2008: 74) conclui que, para elas/es, "o critério principal para escolher uma fonte deve ser a competência, e não o fato de ela representar um lado de uma polêmica". Para além de insistir em uma objetividade suposta possível, em que jornalistas retratariam o mundo de forma imparcial, o que esta afirmação não nos diz, e aqui nos parece mais importante, é que a competência é, também, um valor socialmente construído e legitimado (desde logo incompatível com a noção positivista de 'objetividade' anteriormente referida).

A anterior consideração está em concordância com a Teoria Estruturalista (Hall et al., 1999), segundo a qual, no jornalismo noticioso, face às exigências do mercado, jornalistas se tornam dependentes de fontes institucionais, "pois só entidades burocratizadas têm capacidade para manter o fluxo rotineiro de informação verídica, credível e autorizada de que as organizações noticiosas necessitam" (Sousa, 2002: 14), contribuindo dessa forma para a transmissão das ideologias dominantes e fabricando uma falsa sensação de consenso social. Mesmo reconhecendo que para isso contribuem vários fatores, desde logo a estrutura de propriedade capitalista 
em que os/as profissionais atuam e onde a sua autonomia aparenta estar cada vez mais reduzida, pautada pela proletarização², não é produtivo, sequer justo, 'absolver' as/os jornalistas da responsabilidade que ocupam dentro dessa maquinaria especializada em (re)produzir mundos.

Afirmando terem a imparcialidade, equilíbrio e objetividade como princípios orientadores (sem que muitas vezes esses mesmos princípios sejam devidamente contextualizados e discutidos ao nível dos seus efeitos), jornalistas privilegiam fontes 'dignas de crédito', 'competentes', assim compreendidas mediante dois critérios fundamentais: 0 de autoridade e de papel social. 0 primeiro diz-nos que quanto maior for o nível da autoridade, mais divulgadas serão as suas mensagens: sempre que reconhecida como "uma parte substancial da sociedade, a mídia consolidará essa autoridade. Portanto, existe uma discriminação dos indivíduos que terão acesso aos meios de comunicação" (Alsina, 2009: 189). 0 segundo princípio baseia-se na noção de que o valor da informação depende da origem social do indivíduo e do papel que este desempenha na sociedade.

Deste modo, os media tendem, fiel e imparcialmente, a reproduzir simbolicamente a estrutura de poder existente na ordem institucional da sociedade. Isto é o que Becker chamou «a hierarquia da credibilidade» - a probabilidade daqueles que em posições poderosas ou de elevado status na sociedade, e que dão opiniões sobre os tópicos controversos, de terem as suas definições aceites, porque tais porta- vozes são considerados como tendo acesso a informação mais precisa ou especializada em assuntos particulares do que a maioria da população (Hall et al., 1999: 229).

Este processo, que reforça o estatuto dos sujeitos socialmente privilegiados como definidores primários dos temas e interpretações a ganharem visibilidade pública - mesmo os "argumentos contrários a uma interpretação primária são obrigados a inserirem-se na sua definição de "o que está em questão»" (Hall et al., 1999: 230, grifos dos autores), o que pode ser facilmente observável nas (raras) notícias em que pessoas trans são consideradas como fontes dignas de crédito (desde que dentro de um enquadramento específico) - resulta em narrativas desvinculadas dos - ou melhor, que invisibilizam os - marcadores sociais (como classe, gênero e raça, entre outros) que as constituem, assim contribuindo para o silenciamento de sujeitos construídos como subalternos. Ao nos referirmos a sujeitos subalternos, não aludimos a todo e qualquer um que seja marginalizado, mas àqueles que não têm sua voz reconhecida, que existem publicamente nos termos de outros que falam por eles, enfim, às "camadas mais baixas da sociedade, constituídas pelos modos específicos de exclusão dos mercados, da representação política e legal, e da possibilidade de se tornarem membros plenos no estrato social dominante" (Spivak, 2000 apud Almeida, 2010: 12). Referimo-nos, portanto, a pessoas trans no Brasil, a partir da forma como são representadas no jornalismo brasileiro.

Numa afirmação talvez demasiado extremada pela universalidade que subentende, Molotch e Lester (1999: 50) afirmam ver a mídia não refletir "um mundo exterior mas as práticas daqueles que detêm o poder de determinar a vivência dos outros". É este fenômeno - que deve ser percebido de forma mais abrangente (e possível de ser contrariado), não limitada ao jornalismo, pois as regras que exigem o recurso a 
fontes identificadas como inquestionavelmente credíveis (e como se chega a constituir/perceber tal credibilidade) estão fundamentadas em formas socialmente estruturadas de compreender o mundo e suas instituições (Tuchmann, 1983: 98) - que 0 jornalismo precisa encarar como um desafio urgente, constituinte da sua identidade, fundamentada na legitimidade de falar em favor do interesse (do seu) público. Que público é esse? Recuperemos as funções que apontamos como centrais no jornalismo (mediação, socialização e interpretação): que mediação é essa que não considera as vozes de um dos lados da equação (ou, quando o faz, é, como já defendemos, dentro de uma perspectiva colonialista)? Que questionamentos cabem dentro de uma narrativa quase-única? Que possibilidades de identificação existem, em que termos, frente a estórias construídas com base em enquadramentos de doença e crime? Como escapar ao isolamento social? Como construir laços? Como existir?

De que jornalismo, de que sociedade, nos falam as notícias sobre pessoas trans?

\section{Considerações finais.}

Um mundo governado pela incapacidade de estabelecer sentidos comuns, relativamente estáveis, significaria a impossibilidade de nos comunicarmos, de estabelecer relações sociais, de construir identidades e identificações, de nele nos orientarmos e agirmos, em último caso, de existirmos. Apontamos desta forma 0 paradoxo que na modernidade atravessamos: apesar do seu pluralismo constitutivo colocar em evidência novas possibilidades de vida, entrando em conflito com a tradicional organização centralizada nas instituições produtoras de sentidos e valores (quase) universais, os sujeitos continuam a precisar de mapas de significados normativos que os ajudem a navegar no mundo cada vez mais complexo (tanto política como culturalmente). 0 ponto central deste debate parece-nos ser, portanto, em relação à forma, já não apenas ao conteúdo, como tais significados são construídos. Este aspeto é particularmente interessante de pontuar se tivermos em conta as "maiorias silenciosas" (Louro, 2004: 28) - e silenciadas - que, por meio de movimentações sociais contestatórias, apontam o fosso entre a realidade esperada e a realidade vivida.

Em sociedades como a nossa, que constantemente proclamam a existência de direitos universais (como sejam os de direito à vida, liberdade e igualdade) mas que sempre falham na sua concretização, torna-se inevitável o questionamento: que sentidos têm esses valores para, por exemplo, pessoas trans, pessoas negras, mulheres, não heterossexuais, da periferia, pobres? Que vidas têm direito a ser reconhecidas como humanas? Como e quem chega a construir tais sentidos? Esses e outros questionamentos, feitos a custa de sofrimento mas também com ganhos de liberdade (Berger \& Luckmann, 2004: 54), ao colocarem ênfase na incompatibilidade entre 0 'ser' e 'dever ser' moralmente cobrado, não resultam na inevitável incapacidade dos indivíduos agirem no mundo, tolhidos pelo medo, apenas vagando por planícies de significados com que não se conseguem identificar, pelo contrário, constituem-se também enquanto motores de busca de novas identificações, construções que possibilitam a reorganização dos indivíduos em torno de "tipificações, classificações, padrões de experiência e esquemas de ação" (Berger \& Luckmann, 2004: 18), a partir das quais se assumem como atores na discussão da(s) realidade(s) com que comunicam. 
Ambicionando familiarizar "o cidadão comum com outros cidadãos comuns que usam uma lógica e uma gramática próprias da sua tradição ou com outras províncias de significado cujas lógica e gramática são precisamente distintas da do homem comum" (Correia, 2007: 7), o jornalismo reivindica para si a legitimidade de ocupar uma posição central na organização social. Pensar a legitimidade de tal posição, sua forma e conteúdo, suas potências e riscos, é urgente, principalmente quando tal é feito em relação a pessoas social, cultural e historicamente violentadas, tanto simbólica como fisicamente.

É inegável a preponderância que os meios de comunicação social ocupam na atualidade, desempenhando a importante função de conectar

a experiência coletiva e a individual, oferecendo interpretações típicas para problemas definidos como típicos. Tudo o que as outras instituições produzem em matéria de interpretações da realidade e de valores, os meios de comunicação seleccionam, organizam (empacotam), transformam, na maioria das vezes no curso desse processo, e decidem sobre a forma de sua difusão (Berger \& Luckmann, 2004: 68).

Importa, portanto, para pensar o jornalismo, estudar os conhecimentos que são colocados em circulação e, mais, estudar aqueles que são rejeitados (porquê e como).

Se, como tantas vezes já afirmado, o jornalismo atravessa novamente um momento de crises e mudanças, questões como as aqui apresentadas não podem ficar apartadas dos debates. Se a pretensão for trabalhar contra a subalternidade, em vez de falar pelo(s) sujeito(s) subalterno(s), por que caminhos poderá isso ser perseguido?

\footnotetext{
${ }_{1}^{1}$ Recuperado em 11 de abril de 2016, de [http://www.transrespect-transphobia.org/en_US/tvt-project/tmm-results/idahot- 2015.htm] e [http://www.transrespect-transphobia.org/uploads/downloads/2015/TMM-IDAHOT2015/TVT- TMM-Tables_IDAHOT-2015_EN.pdf].

2 Entendemos 'proletarização' como um processo em que "as condições de trabalho conduzem numerosas profissões à condição de assalariados [... Esta proletarização implica o declínio de competências e qualificações dos profissionais e da sua autonomia de trabalho, graças a um processo em que pela fragmentação, desqualificação e rotinização das actividades profissionais, os trabalhadores tornar-se-iam cada vez mais meros executantes" (Fidalgo, 2008 apud Correia, 2011: 155).
}

REFERÊNCIAS BIBLIOGRÁFICAS

Almeida, S. (2010). Prefácio. In: Spivak, G. (ed.) Pode o subalterno falar? Belo Horizonte, Editora UFMG.

Alsina, M. R. (2009). A construção da noticia. Petróplis: Editora Vozes.

Amaral, M. F. (2006). Jornalismo popular. São Paulo: Contexto.

Associação Nacional de Travestis e Transexuais do Brasil - ANTRA. (2013) Nota Circular $n^{\circ}$ 0001/2013 - Presidência - 2012/2016. A Mídia e Meios de Comunicação Local e Nacional. In: (https://homofobiamata.files.wordpress.com/2013/01/antra1.pdf) (acedido 10/05/2016).

Benetti, M. (2010). Análise do discurso em jornalismo: estudo de vozes e sentidos. In: Lago, C. \& Benetti, M. (ed.) Metodologia de pesquisa em jornalismo. Petrópolis: Vozes. 
Bento, B. (2006). A reinvenção do corpo: sexualidade e género na experiência transexual. Rio de Janeiro: Garamond.

Berger, P. L \& Luckmann, T. (2004). Modernidade, Pluralismo e Crise de sentido: A orientação do homem moderno. Petrópolis: Vozes.

Coelho, P. (2015). Jornalismo e Mercado: os novos desafios colocados à formação.

Covilhã: Labcom Books..

Correia, J. C. (1998). Algumas reflexões sobre a importância da formação universitária dos jornalistas. In: (http://www.bocc.ubi.pt/pag/correia-joao-formacao-universitaria-jornalistas.pdf) (acedido 9/05/2016).

Correia, J. C. (2007). Linguagem jornalística, estranheza e referência. In: (http://www.bocc. ubi.pt/pag/correia-joao-linguagem-jornalistica-estranheza-referencia.pdf) (acedido 9/05/2016).

Correia, J. C. (2011). O Admirável Mundo das Notícias: Teorias e Métodos. Covilhã: Labcom Books.

Foucault, M. (1999). Vigiar e punir - nascimento da prisão. Petrópolis: Vozes.

Hall, S. et al. (1999). "A produção social das notícias: 0 mugging nos media». In: Traquina, N. (Org). Jornalismo: Questões, Teorias e "Estórias». Lisboa: Vega.

Jesus, J. G. (2014). Transfobia e crimes de ódio: Assassinatos de pessoas transgênero como genocídio. História Ágora 16: 101-123.

Lopes, P. (2010). Jornalismo e linguagem jornalística: Revisão conceptual de base bibliográfica. In: (http://www.bocc.ubi.pt/pag/bocc-lopes-linguagem.pdf) (acedido 07/05/2016).

Louro, G. L. (1997). Gênero, sexualidade e educação: uma perspectiva pós- estruturalista. Petrópolis: Vozes.

Louro, G. L. (2004) Um corpo estranho, ensaios sobre sexualidade e teoria queer. Belo Horizonte: Autêntica.

Miskolci, R. (2005). Do desvio às diferenças. Teoria e Pesquisa 9: 9-41.

Molotch, H. \& Lester, M. (1999). As notícias como procedimento intencional: acerca do uso estratégico de acontecimentos de rotina, acidentes e escândalos. In: Traquina, N. (Org). Jornalismo: Questões, Teorias e "Estórias». Lisboa: Vega.

Rocha, H. C. L. (2009) A crítica de Habermas ao cientificismo: uma proposta de pluralismo epistêmico. Symposium 1: 175-193.

Rocha, H. C. L. (2008). Habermas e a Teoria do Jornalismo: a manipulação ideológica no jornalismo como distorção sistemática da comunicação. Estudos em Comunicação 4: 41-57.

Sousa, J. P. (2002). Construindo uma teoria do jornalismo. In (http://www.bocc.ubi.pt/pag/ sousa-jorge-pedro-construindo-teoria-jornalismo.pdf) (acedido 05/05/2016).

Sponholz, L. (2008). As objetividades do jornalista brasileiro. Líbero 21: $69-78$.

Sunkel, G. (1987). La representación del pueblo en los diarios de masas. Diálogos de la Comunicación, 17.

Tuchman, G. (1983). La producción de la noticia - estudio sobre la construcción de la realidad. Barcelona: Gustavo Gili.

Vieira, H. (2015). Coisa que "lugar de fala" não é. In:. (https://www.facebook.com/dantasdantasvieira/posts/1003753229689724) (acedido 29/12/2015). 